\title{
Revisiting the UsersAward Programme from a Value Sensitive Design Perspective
}

\author{
Åke Walldius \\ KTH Royal Inst. of Technology \\ SE-100 44 Stockholm, Sweden \\ aakew@kth.se
}

\author{
Jan Gulliksen \\ KTH Royal Inst. of Technology \\ SE-100 44 Stockholm, Sweden \\ gulliksen@kth.se
}

\author{
Yngve Sundblad \\ KTH Royal Inst. of Technology \\ SE-100 44 Stockholm, Sweden \\ $\mathrm{y} @$ kth.se
}

\begin{abstract}
The goal of the UsersAward (UA) programme is to develop and maintain a strategy for enhancing the quality of workplace software through on-going user-driven quality assessment. Key activities are development of sets of quality criteria, as the USER CERTIFIED 2002 and 2006 instruments, and performing large domain specific user satisfaction surveys building on these quality criteria. In 2005 we performed a first analysis of the values that inform the criteria and procedure making up the 2002 instrument, using the Value Sensitive Design methodology. This paper is a follow-up of that study. We report on new types of stakeholders having engaged with the UA programme and reflect on how the conceptual considerations and explicit values of the programme have shifted as a consequence.
\end{abstract}

\section{Keywords}

UsersAward programme, user satisfaction surveys, userdriven certification of software, workplace IT, Participatory Design, Value Sensitive Design

\section{ACM Classification Keywords}

H.5.3 Group and Organization Interfaces

\section{INTRODUCTION}

The Human-Computer Interaction (HCI) and Information Systems research communities are moving from studying design and deployment of IT into the workplace to the digitalization of society as a whole. IT is no longer considered a separate component in working life, but one of the driving forces for social and technical innovation. The digitalization process means that a number of work tasks are disappearing [3]. Often it is the physically heavy routine tasks and jobs requiring no or little education that are affected. In the future the demands for highly educated workers will increase and consequently new requirements are put on the working staff, with increased pressure and stress as a consequence. This makes it important to consider a wider spectrum of values affected by the introduction of IT in work and societal contexts.

Copyright $\subset 2015$ is held by the author(s). Publication rights licensed to Aarhus University and ACM

5th Decennial Aarhus Conference on Critical Alternatives August $17-21$, 2015, Aarhus Denmark

DOI: http://dx.doi.org/10.7146/aahcc.v1i1.21317
The UsersAward (UA) programme was launched in 1998, initiated by the LO (Swedish Trade Union Confederation) in cooperation with the TCO (Swedish Confederation for Professional Employees) and a group of researchers from KTH (as research coordinator), Uppsala University, Gävle University, and Luleå Technical University.

The UsersAward programme follows the "Scandinavian tradition" of involving users in IT development for use at workplaces. In the seminal Utopia project in the 1980s the focus was on user involvement in the design and development of the IT support [7]. The investigations and opinion making activities the UA programme has performed since its inception (domain specific user surveys, software certifications, prize competitions) indicate that the users also have to participate in the procurement, deployment, periodic screenings and further development of the software [9]. The motivation for the first analysis of the UA programme from the Value Sensitive Design (VSD) perspective was "to understand how the principled and systematic approach to designing for human values that Value Sensitive Design offers can further the understanding of when and how different stakeholders can contribute to IT design, development, and deployment in a sustainable and mutually beneficial way" [10]. The aim of this follow-up paper is to report on new participants in, and activities and results of, the UA programme since 2005 and to reflect on how some of the conceptual considerations and explicit values have shifted as a consequence of the programme's development.

We briefly summarize the UA programme, VSD as a critical screening perspective and the main findings regarding how a better understanding of direct and indirect stakeholder values involved may benefit the future development of the UA programme. After that summary we will report on how we have tried to apply the findings from the initial paper.

Since 2005, there has been a growing public awareness of how low quality IT systems negatively affect the work environment in several sectors of society. We argue that this increased awareness provides future challenges and possibilities for HCI research in general and for the UA programme in particular. We conclude the paper by briefly describing how the participation of new stakeholders has resulted in new methods for investigating how software can 
benefit both user self-direction and the economic health of organisations using the software.

\section{THE USERSAWARD PROGRAMME}

Between 1998 and 2011 the UA programme developed and performed a unique combination of industry wide user surveys, user conferences, targeted design projects, yearly IT Prize contests, and, as the main research challenge, a Users' certification instrument and procedure for workplace software packages [5]. The 2005 VSD screening of the programme focused on the certification instrument [10]. We briefly outline the rationale and procedure for the USER CERTIFIED 2002 and 2006 instruments.

\section{The rationale behind the User Certified instrument}

The inspiration for the UA programme was the successful certification programme for display units, TCO'92, launched by TCO in 1992 through a broad cooperation between TCO, researchers and environmental organisations. This certification programme had been regularly upgraded (TCO'95, TCO'99, TCO CERTIFIED) and had by 2002 put its label on more than 200 million display units worldwide, [2].

LO wanted the UA initiative to develop a similar model for the workplace software market. The goal was to develop a method that was user-driven, both in the sense that it was initiated by, and developed in cooperation with, Sweden's two largest employee organizations $(2+1.3$ million members), and in the sense that the certificate each software package received was based on end-users from at least two different workplaces who, after having operated the software for more than nine months, had given it their seal of approval.

\section{Applying the User Certified 2002 and 2006 instruments} We briefly summarize the USER CERTIFIED instrument, its design and our experience from applying it in eight certification processes. For more comprehensive descriptions see $[5,9]$.

The assessment procedure starts by asking a software provider, who applies for certification, to fill out a selfdeclaration regarding the software and its intended use and to suggest three workplaces where the user satisfaction of the package can be assessed. The main activity is the set of interviews and questionnaire surveys that the evaluation team carries out at the three workplaces. 29 quality criteria in the certification questionnaire are presented as statements to be confirmed on a value scale from 1 (total dismissal) to 6 (total agreement). At each of the three workplaces, three end-users and three representatives from management are interviewed separately, based on the questionnaire. Also 10\% (or at least 10) of the software's end-users answer a user version of the questionnaire.

The questionnaire covers six areas (totally 29 statements): Overall benefits, Deployment method, Technical features, Worktask support, Communicative support, Local assessment. The users are considered satisfied as a whole, and a certificate is issued, when at least two of the investigated workplaces meet the required level of agreement with the 29 statements. If successful a detailed protocol is published, with quotes from the users' free-form comments on all pertinent issues. The 2006 revision of the instrument was prompted by an interest from German unions and researchers, who, after having replicated surveys based on the UC 2002 instrument [6], argued for an adaptation of some of the quality criteria and more realistic levels of acceptance in respect to the difference between German and Scandinavian work organisation and team autonomy. In 2005, three software packages had received the USER CERTIFIED 2002 label. Between 2005 and 2009 three more packages passed the user satisfaction screenings. Furthermore, two of the packages applied for, and passed, new USER CERTIFIED screenings in 2007 and 2009 respectively.

\section{VALUE SENSITIVE DESIGN}

Value Sensitive Design (VSD) is a theoretically grounded approach to design of technology that seeks to account for human values in a principled and comprehensive manner throughout the design process [4]. The approach is today an acknowledged approach in HCI. Here is a brief summary.

In VSD values are viewed neither as inscribed into technology nor as simply transmitted by social forces. People and social systems affect technological development, and technologies shape individual behaviour and social systems. It is a tripartite methodology, consisting of conceptual, empirical, and technical investigations, which are applied iteratively and integratively. Conceptual investigations comprise philosophically informed analyses of the central constructs and issues under investigation. Empirical investigations focus on the human response to the technical artefact, and on the larger social context in which the technology is situated, using methods from the social sciences. Technical investigations focus on the design and performance of the technology itself.

A key aspect of Value Sensitive Design is its focus on both direct and indirect stakeholders. The direct stakeholders include the users of the system in question, the system developers, and the managers of both users and developers. The indirect stakeholders are not direct users of the system, but nevertheless affected by the system, either positively or negatively. For example, the direct stakeholders for a hospital scheduling system might be doctors, nurses, and other hospital personnel. Two important classes of indirect stakeholders would be the patients and their families - even though they don't use the system directly, they are strongly affected by it.

\section{RESULTS FROM THE 2005 VSD SCREENING}

Furthermore, VSD makes a distinction between explicitly supported values (i.e., ones that we explicitly adopt and support throughout the design of the system), and stakeholder values (i.e., ones that are important to some but not necessarily all of the diverse stakeholders for that system). In the 2005 screening we found that "the principal explicitly supported values of the UsersAward programme 
itself are transparency and fairness: transparency, because we want the process by which software packages are certified to be open and understandable; and fairness, because we want the certification assessment to be made in an unbiased manner." [10]

For the evaluated systems, the screening found that "the values the programme attempts to foster are all related to human welfare and human flourishing. They include: competency development for the individual, the team, and the organization as a whole (in particular opportunities for exploration and learning); enhanced degree of self-direction for individual workers and teams; supporting flexible, selfdirected communication within and between work teams; and economic health of the organization using the system." VSD calls on the investigators to consider indirect as well as direct stakeholders, and harms in addition to benefits. The 2005 screening of the UA programme resulted in a recommendation "that the certification instrument articulates in a more systematic way questions about who are the indirect as well as the direct stakeholders, and about the harms as well as benefits of the system for the different stakeholder groups." [10] The empirical investigations proposed in the 2005 screening aim at clarifying "how well the UsersAward programme supports the values of transparency and fairness [and] how well it fosters the values listed above in the systems being evaluated - and whether there are other values that should be added to the list, or values that should be clarified or subsumed." [10]

\section{CONTEXTUAL CHANGES AND RESEARCH SINCE 2005}

The 2005 VSD screening exercise was very important for our own understanding of the UA activities. We were fortunate to have Alan Borning, one of the most knowledgeable proponents of the approach, as co-author. However, the closest we have been to a renewed meta level screening is a small (109 respondents) survey study carried out in 2009 in order to gauge the needs of different stakeholders interested in the programme and responding to the survey - buying companies, user organisations, public agencies, municipalities, IT providers, IT consultants and universities [1]. Although the study was not done along the VSD lines of thought it resulted in some reconsiderations of the UA values which we will briefly mention below. In the absence of a systematic VSD analysis the following points of self-assessment can be seen as preparation for such a study when we (or, preferably, external reviewers) get the means of conducting one. First, we will account for two major changes in the environment of the UA programme since 2005. Then we will try to pinpoint what this has meant for the adherence to UA's explicit values in the UA practice and to our reconsiderations of these values.

\section{Changes in the UA programme environment}

The first major change regarding the context for the UA programme is that the individual trade unions have started to perform IT user satisfaction surveys of their own memberships. The biggest union for white collar workers,
Unionen, has made surveys in 2008, 2010, 2012, 2013 and 2015 [8]. And in 2013 the union for civil and municipal servants, Vision, made their first survey. These surveys are based on UA surveys of industry, health care and banks performed in 2002, 2004, and 2005 respectively, surveys which in turn were based on the UA certification values and criteria [5].

Related to increased activism of individual unions was a shift of ownership of the UA programme. As of this writing, TCO Development has just acquired the programme, methods and databases. With its 20 years experience of environmental labelling of IT hardware (http://tcodevelopment.com) a new challenge for the UA research and development now is to complement the TCO Certified label designed to support the values of hardware ergonomics and the social responsibility of IT manufacturers with the UsersAward label for IT workplace software usability. This, also, calls for a reorientation of the UA research.

Are UA's declared explicit values of 2005 still relevant? For the UA programme as a whole, we interpret an increased union activism and a more resourceful owner as benefitting an increased awareness of concrete usability problems at Swedish workplaces. Other UA initiatives we regard as supporting the transparency and fairness of the programme are the pilot study mentioned above [1], and two international research workshops arranged around the concept of User-driven IT Design and Quality Assurance (UITQ), which led to, among other things, two replications of UA certification studies by a German research group [5].

The growing series of union reports, which typically cover a randomised sample of about 2000 users responding to about 30 statements, clearly show that users experience no or only a slow increase in the explicit values in systems that $U A$ promote - competency development, self-direction, and economic health of the organisation [8]. The most alarming results concern the lack of self-direction - users are not allowed to participate in the deployment of new systems in the four areas problematized in the surveys: how work tasks should be transformed, how functionality should be prioritised, and how education and training should be delivered in order to have the systems support the new ways of working [9]. Under the heading "Four out of ten think that the IT-systems are difficult to use" the Union 2015 report concludes: "Here is a potential for cost reductions for the employers and reduced stress and frustration for the users." [8]

A further indication of the relevance of the values declared in 2005 is the fact that the Swedish health promoting agency Prevent, jointly owned and managed by the employer and employee organisations, has initiated a programme against what they term "TechnoPanic" (http://www.prevent.se/TeknikPanik). This we interpret as a sign that the direct interest of organised users with respect to self-direction and competence is shared by the employer organisations with their more direct interest in the 
economic health of the member companies they serve through the Prevent health programme.

\section{RECONSIDERING EXPLICIT VALUES}

The survey study in 2009 shed some light on one of the questions raised in 2005 - which other stakeholders should be involved in user-driven IT quality assurance? The results indicated that both user organisations and universities ranked higher as trustworthy institutions than public agencies and private companies [1]. The non-profit company TCO Development (TCO-D, new owner of UA) represents a special case, as it is in turn owned by a trade union confederation. But more than that, the clients of TCO-D are not only the federated unions and their membership. TCO-D also addresses management representatives of hardware and software providers directly with certification services. This in turn moves the economic health of companies, specifically through more selfdirection for the users, to the forefront as an explicit value for a renewed UA programme.

Anticipating the TCO-D future involvement in UA, the UA research 2009-2011 focused on understanding economic impacts of managing usability. A new format for analysing and presenting results from certification was developed [5]. The instrument applies strategy maps, a tool developed by Kaplan \& Norton for facilitating iterative, collaborative deliberation among stakeholders on strategic issues. As of this writing, we have only used usability strategy maps in certification protocols and in minor field studies. The most visible foregrounding of usability efforts contributing to economic health is the new survey question "How much time would you save per day if the IT-systems worked the way you wanted?" This question has yielded stable member estimations of around 25 minutes per day, resulting in assessments of overall potential savings of more than 10000 MSEK a year for the Unionen membership alone [8]. Through collaboration within the Nordic eHealth Network (NeRN), mandated by the Nordic Council of Ministers, this question has in turn been taken up in similar user satisfaction surveys in some of the other Nordic countries [11].

\section{CONCLUSION}

VSD is usually employed in guiding the design of individual information systems. In the preliminary screening of the UA programme in 2005, we used VSD to inform the design of a programme intended to impact the design of computer systems - in other words, we were working one level removed from the design of the individual IT system. In this revisit of the UA programme, we conclude that the programme's explicit values are the same as 2005 , although there has been a shift towards understanding the mutual interplay between user selfdirection and economic values of IT usage. TCO
Development's focus on challenging hardware and software providers to live up to high quality standards has underlined the importance of investigating how investments in usability may result in better work environment as well as a sustained or increased level of economic health for the organisations that use good quality software.

\section{ACKNOWLEDGMENTS}

This research was supported in part by Swedish Agency for Innovation Systems (VINNOVA).

\section{REFERENCES}

1. Bengtsson, L., Ivarsen, O., Lind, T., Olve, N., Sandblad, B., Sundblad, Y., Walldius, Å. (2009). Nya initiativ för användbarhetsarbetet - en pejling av behovet hos UsersAwards olika interessentgrupper. TR TRITACSC-MDI 2009

2. Boivie, P.E. (2007). Global standard - how computer displays worldwide got the TCO logo, Premiss (2007).

3. Frey, C. B. \& M. A. Osborne, "The Future of Employment: How Susceptible Are Jobs to Computerisation?" Oxford University manuscript, 2013.

4. Friedman, B. (ed.) Human Values and the Design of Computer Technology, Cambridge University Press and CSLI, New York, NY and Stanford, CA, 1995.

5. Ivarsen O., Lind T., Olve N.-G., Sandblad B., Sundblad Y. \& Walldius Å. (2011). Slutrapport UsersAward2 utvecklad kvalitetssäkring av IT-användning, MID, CSC, KTH.

6. Prümper, J., Vöhringer-Kuhn, T. \& Hurtienne, J.: UsersAward - First results of a Pilot Study in Germany, In Proceedings of the UITQ 2005 workshop.

7. Sundblad, Y.: UTOPIA - Participatory Design from Scandinavia to the World, in Proceedings History of Nordic Computing 3, pp. 176-186. Springer Verlag, Heidelberg (2010).

8. Unionen (2015). Tjänstemännens IT-miljö 2014 Lyssna på oss som ska använda det", Unionen.

9. Walldius, Å., Sundblad, Y., Sandblad, B., Bengtsson, L., Gulliksen, J. (2009). User certification of Workplace Software - Assessing both Artefact and Usage, BIT (Behaviour \& Information Technology), vol.28, no.2, pp.101-120. (2009)

10. Walldius, Å., Sundblad, Y., Borning, A. (2005). A First Analysis of the UsersAward Programme from a Value Sensitive Design Perspective, in Bertelsen, O., N., O., Bouvin, P., G., Krogh and M., Kyng (eds.), Proceedings of the Fourth Decennial Aarhus Conference August 2024, 2005, pp. 199-202

11.www.norden.org/en/publications/publikationer/2013-522 